\title{
FREQUENCY OF RHABDIASID NEMATODES IN WILD Crotalus durissus terrificus (SERPENTES, VIPERIDAE) FROM BOTUCATU REGION, SÃO PAULO STATE, BRAZIL
}

SILVA R. J. (1), NOGUEIRA M. F. (2), BARRELLA T. H. (3), TAKAHIRA R. K. (4)

(1) Department of Parasitology, Botucatu Institute of Biosciences, São Paulo State University, UNESP, Botucatu, São Paulo State, Brazil; (2) Department of Microbiology and Immunology, Botucatu Institute of Biosciences, São Paulo State University, UNESP, Botucatu, São Paulo State, Brazil; (3) Center for the Study of Venoms and Venomous Animals, São Paulo State University, UNESP, Botucatu, São Paulo State, Brazil; (4) Department of Clinical Veterinary Medicine, School of Veterinary Medicine and Animal Husbandry, FMVZ, São Paulo State University, UNESP, Botucatu, São Paulo State, Brazil.

ABSTRACT: The aim of the present study was to evaluate the frequency of rhabdiasid nematodes in recently captured Crotalus durissus terrificus snakes from São Paulo State, Brazil. Fifty snakes (34 males and 16 females) were studied and each one was evaluated for the presence of that nematode at the moment of receipt at the Institution and after 90 days of quarantine inside individual cages. Tracheopulmonary washes were examined. Snakes that died during quarantine underwent necropsy and lung examination. Analysis of the results obtained at the two evaluation times ( 0 and 90 days), in addition to the data obtained during necropsies, showed that $44 \%$ (18 males and 4 females) of the $C$. $d$. terrificus snakes were naturally infected by rhabdiasid nematodes. These data demonstrate the parasitism level in natural conditions and are important for the sanitary handling of these reptiles in captivity.

KEY WORDS: Rhabdias, Nematoda, frequency, Crotalus durissus terrificus, Viperidae, snakes.

CONFLICTS OF INTEREST: There is no conflict.

\section{CORRESPONDENCE TO:}

REINALDO JOSÉ DA SILVA, Departamento de Parasitologia, Instituto de Biociências, UNESP, 18618-000, Botucatu, São Paulo, Brasil. Phone: +55 143811 6239. Fax: +55 143815 3744. Email: reinaldo@ibb.unesp.br. 
R. J. Silva et al. FREQUENCY OF RHABDIASID NEMATODES IN WILD Crotalus durissus terrificus (SERPENTES, VIPERIDAE) FROM BOTUCATU REGION, SÃO PAULO STATE, BRAZIL. J. Venom. Anim. Toxins incl. Trop. Dis., 2007, 13, 1, p. 123

Breeding snakes in captivity, particularly in a semi-extensive system, is an activity that exposes the animals to the action of several parasites (9). The prevalence of parasites with a monoxenic cycle is higher than that of heteroxenic-cycle parasites, since the latter require an intermediate host to complete their cycle (12). The transmission of monoxenic-cycle parasites is favored by the physical and organic conditions of the captivity, thus a snake can contaminate other animals or even reinfect itself with its own feces. In addition, the captivity conditions or the related stress may be responsible for the acquisition or increase of the parasitic infection (7). Studies on Brazilian snake helminthes, mainly in animals kept in captivity, have been published. Araújo et al. (3) necropsied some specimens of Crotalus durissus terrificus and Bothrops alternatus maintained in captivity. These animals presented anorexia, dehydration, diarrhea, anemia and died approximately two months after the beginning of clinical signs. In these snakes, helminthes of the Kalicephalus, Ophidascaris, Rhabdias and Oxyuris genera were identified. Silva et al. (13) studied the nematodes frequency in 24 specimens of $C$. $d$. terrificus in captivity and found parasites in the stomach (16.7\%), intestine (12.5\%) and lung (70.8\%). In the latter, Rhabdias labiata was the only species found.

Rhabdiasid nematodes parasitize the snake lung and its frequency has been very high $(3,13)$. The data found in literature were obtained from animals in captivity. There are no studies in Brazil on the frequency of these nematodes in wild snakes. Thus, the aim of the present study was to evaluate the frequency of rhabdiasid nematodes among recently captured C. $d$. terrificus snakes from the state of São Paulo, Brazil.

Fifty C. $d$. terrificus snakes were studied. The animals were donated to the Center for the Study of Venom and Venomous Animals, São Paulo State University, UNESP, Brazil. For each animal included in the study, data about origin, sex, length and weight were recorded.

The snakes were evaluated for the presence of rhabdiasid nematodes at the moment of receipt at the Center (day 0 ) and after 90 days of permanence in quarantine inside individual cages. The presence of the nematode was evaluated through macro and microscopic examination of tracheopulmonary washes. Before the washing procedure, the snakes were anesthetized with 22 to $44 \mathrm{mg} / \mathrm{kg}$ of ketamine, intramuscularly, as recommended by Burke (5). Afterwards, a strip of PVC film was 
R. J. Silva et al. FREQUENCY OF RHABDIASID NEMATODES IN WILD Crotalus durissus terrificus (SERPENTES, VIPERIDAE) FROM BOTUCATU REGION, SÃO PAULO STATE, BRAZIL. J. Venom. Anim. Toxins incl. Trop. Dis., 2007, 13, 1, p. 124

carefully rolled up around the fangs of the animal to avoid accidental venom inoculation. To obtain the tracheopulmonary washes, a catheter was inserted through the glottis and trachea and then a volume of sterile phosphate buffered saline (PBS) equivalent to $1 \%$ of the animal weight was injected. The recovery of infused PBS was obtained using a peristaltic pump, at a flow of about $1 \mathrm{ml} / \mathrm{min}$.

The tube containing the tracheopulmonary washes was macroscopically examined for the presence of partenogenetic females. After that, a sample of the wash was subjected to microscopic examination. For this, $100 \mu$ l of the wash were centrifuged in a cytocentrifuge (800rpm, for five minutes) and the slides allowed to dry, before staining with Leishman. The slides were examined using optical microscopy for the presence of eggs and/or larvae of rhabdiasid nematodes. Animals that died during captivity were necropsied and their lungs examined for the presence of this nematode.

Comparison between the number of males and females parasitized was made using the proportion test. Length and weight of the normal and parasitized snakes were compared by t-test. The significance level adopted was of $5 \%$.

In the tracheopulmonary washes obtained at the receipt of the animals, adult female parasites were found in 11 (22\%) snakes. During the microscopical examination, eggs and larvae of rhabdiasid nematodes were also detected in 11 (22\%) and five $(10 \%)$ snakes, respectively. In total, the different forms of the parasite were found in $16(32 \%)$ snakes. Just two (4\%) snakes presented eggs, larvae and adults in the tracheopulmonary washes. In five (10\%) snakes, eggs and adults were found and in other two (4\%), just eggs and larvae were found.

Eight specimens (16\%) died during quarantine, and in four (8\%), the necropsy revealed the presence of adult lung worms. In just one of these cases, the nematode had not been detected during the first evaluation.

At the examination performed after 90 days, the tracheopulmonary washes was positive for the presence of adult partenogenetic female in nine (18\%) snakes and during the microscopical examination, eggs were found in five (10\%) samples. Larvae were not detected at that time. In this second evaluation, rhabdiasid nematodes were demonstrated in five (10\%) snakes whose previous exams (day 0) were negative. In contrast, five snakes whose first exams were positive, presented negative results. 
R. J. Silva et al. FREQUENCY OF RHABDIASID NEMATODES IN WILD Crotalus durissus terrificus (SERPENTES, VIPERIDAE) FROM BOTUCATU REGION, SÃO PAULO STATE, BRAZIL. J. Venom. Anim. Toxins incl. Trop. Dis., 2007, 13, 1, p. 125

Analysis of the results obtained at the two evaluation times ( 0 and 90 days), in addition to the data obtained during the necropsies, showed that $44 \%$ of the $C$. $d$. terrificus snakes were naturally infected by rhabdiasid nematodes.

The snakes included in this study were from the rural area of 13 cities of São Paulo State, Brazil (Anhembi, Bofete, Botucatu, Cerqueira Cesar, Conchas, Fartura, Ibitinga, Itaporanga, Itatinga, Laranjal Paulista, Piraju, Salto and Santa Maria da Serra). However, most of the snakes were from Botucatu (48\%), Santa Maria da Serra (8\%), Bofete (6\%) and Conchas (6\%). The origin of three (6\%) snakes was not informed. Among the infected snakes $(n=22), 13$ were from Botucatu. Each snake was captured and transported to the laboratory in an individual container. The time between the capture and the arrival at the laboratory was two days (median value), with a range from zero to 33 days. For eight animals, these data were not obtained.

The mean length and the weight recorded for the non-parasitized animals were $92.4 \pm 9.3 \mathrm{~cm}$ and $486.4 \pm 171.2 \mathrm{~g}$, respectively. The mean length and the weight for the parasitized snakes were $97.5 \pm 13.3 \mathrm{~cm}$ and $550.7 \pm 295.6 \mathrm{~g}$, respectively. Length $(p=0.11)$ and weight $(p=0.34)$ were not statistically different between parasitized and non-parasitized snakes.

With regard to sex, the studied sample was constituted of 34 males and 16 females. Four out of the 16 studied females were parasitized while, in the males, parasitism was verified in 18 out of the 34 studied animals. There was no statistically significant difference between these proportions $(p=0.12)$.

The adult female found in the snake lungs presented cephalic extremity with six lips, a reduced buccal capsule, claviform esophagus, a visible nerve ring, a vulva in the middle of the body, didelphic and amphidelphic uterus, and larval eggs (Table 1, Figure 1). Morphological analysis demonstrated that these nematodes belonged to the genus Rhabdias. This genus identification was based on descriptions available in literature $(10,11)$.

The present study was carried out to evaluate the parasitism by rhabdiasid nematodes in wild snakes. The study was proposed because we observed that, in captivity, C. $d$. terrificus snakes presented a high prevalence (above 70\%) of infection by these nematodes (13). The present investigation showed that $44 \%$ of the snakes analyzed arrived for captivity already infected by Rhabdias sp. This data is important for the sanitary handling of these animals during captivity. 
R. J. Silva et al. FREQUENCY OF RHABDIASID NEMATODES IN WILD Crotalus durissus terrificus (SERPENTES, VIPERIDAE) FROM BOTUCATU REGION, SÃO PAULO STATE, BRAZIL. J. Venom. Anim. Toxins incl. Trop. Dis., 2007, 13, 1, p. 126

The difference between the prevalence observed in wild and captivity animals can be explained by the fact that rhabdiasid nematodes present a monoxenic cycle, whose transmission is favored by the physical and organic conditions of the captivity, in which infected snakes can contaminate themselves or other animals with their own feces (7). Thus, the reduced space in the captive environment increases the chance of infection.

An association between the occurrence of pulmonary nematodes and the snake length, weight and sex was not observed. These data demonstrate that the infection is disseminated among wild snakes and that it causes no changes in the biometric parameters of these animals. The present study did not permit us to make any conclusions regarding the geographical distribution of these nematodes. The parasitized snakes were from a number of cities from São Paulo State and no predominant region was observed.

In Brazil, snake lung nematodes belong to the family Rhabdiasidae, which has two genera: Acanthorhabdias and Rhabdias. The first one just contains the species $A$. acanthorhabdias $(4,6)$ and, within the second, there are two species described: $R$. vellardi and $R$. labiata $(10,11)$.

The species of the genus Rhabdias present a parasitic phase that include a partenogenetic female, found in the lung of snakes, and a free-living phase, with the occurrence of free-living males and females (1). Kloss (8) reported that it is very difficult, or practically impossible, to characterize one species of the genus Rhabdias just by the analysis of the partenogenetic female, pointing out that, for the characterization of the rhabdiasid species, the description of all the forms of the parasite is necessary.

The biological cycle for the characterization of the species involved in the parasitism was not accomplished in the present study. Our interest was just to evaluate the percentage of snakes that arrived for captivity infected by lung nematodes of the family Rhabdiasidae. However, in all samples where adult partenogenetic females were recovered, the buccal capsule was reduced, with a thin wall devoid of onchia and the cephalic extremity presented six lips, which are characteristics of the genus Rhabdias $(2,10,11)$. These data showed that the snakes included in the study were parasitized by $R$. labiata or $R$. vellardi. 
R. J. Silva et al. FREQUENCY OF RHABDIASID NEMATODES IN WILD Crotalus durissus terrificus (SERPENTES, VIPERIDAE) FROM BOTUCATU REGION, SÃO PAULO STATE, BRAZIL. J. Venom. Anim. Toxins incl. Trop. Dis., 2007, 13, 1, p. 127

The infected animals were diagnosed by the examination of tracheopulmonary washes. This methodology has not been frequently used in helminthological studies. In most of these studies, diagnosis was based on coproparasitological exams. However, the tracheopulmonary washes allows detection of the parasite specifically in the parasitized organ, which can result in positive tests even when the adult females are not yet producing eggs, a situation in which coproparasitological examinations would give negative results.

The data obtained in the present study clearly demonstrated that $C$. d. terrificus snakes, in natural conditions, present high infection rates of lung nematodes from the family Rhabdiasidae. In snakes, Rhabdias spp. can cause a "verminous" pneumonia, characterized by gaping mouth, wheezing, and exudates from trachea $(7,9)$. Control measurements during snake handling are necessary for the control of infection by these helminthes when the snakes are kept in captivity.

Table 1. Morphometric data of partenogenetic female of Rhabdias sp. from Crotalus durissus terrificus lung in Brazil.

\begin{tabular}{lccc}
\hline \multirow{2}{*}{ Variables } & \multicolumn{3}{c}{ Morphometric data $(\mu \mathrm{m})$} \\
\cline { 2 - 4 } & Mean & Minimum & Maximum \\
\hline Length & 4603 & 3648 & 5500 \\
Width & 247 & 169 & 330 \\
Esophagus length & 297 & 258 & 346 \\
Distance from nerve ring to anterior extremity & 148 & 125 & 171 \\
Distance from vulva to anterior extremity & 2217 & 1549 & 2536 \\
Distance from anus to posterior end & 132 & 95 & 181 \\
Egg & & & \\
$\quad$ Length & 84 & 71 & 96 \\
$\quad$ Width & 42 & 35 & 49 \\
\hline
\end{tabular}


R. J. Silva et al. FREQUENCY OF RHABDIASID NEMATODES IN WILD Crotalus durissus terrificus (SERPENTES, VIPERIDAE) FROM BOTUCATU REGION, SÃO PAULO STATE, BRAZIL. J. Venom. Anim. Toxins incl. Trop. Dis., 2007, 13, 1, p. 128
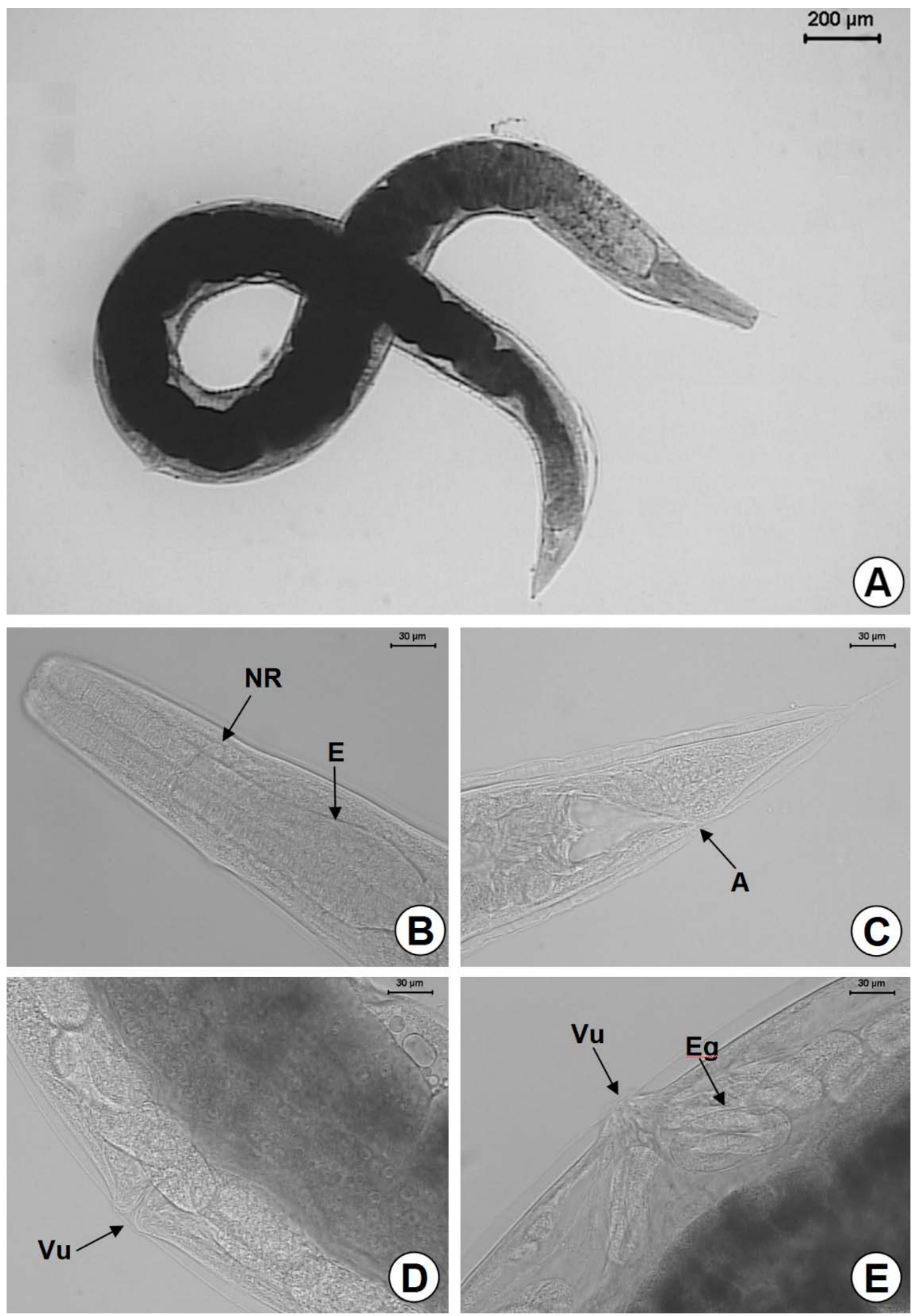

Figure 1. Rhabdias sp. from Crotalus durissus terrificus lung. A) General view of the partenogenetic female; B) Detail of the esophagus (E) and nerve ring (NR); C) Anus (A); D) Vulva (Vu); E) Larval egg (Eg) inside the uterus. 
R. J. Silva et al. FREQUENCY OF RHABDIASID NEMATODES IN WILD Crotalus durissus terrificus (SERPENTES, VIPERIDAE) FROM BOTUCATU REGION, SÃO PAULO STATE, BRAZIL. J. Venom. Anim. Toxins incl. Trop. Dis., 2007, 13, 1, p. 129

\section{REFERENCES}

1 ANDERSON RC. Nematode parasites of vertebrates: Their development and transmission. New York: CABI Publishing, 2000: 650p.

2 ANDERSON RC., BAIN O. Keys to the genera of the Superfamilies Rhabdtitoidea, Dioctophymatoidea, Trichinelloidea and Muspiceoidea. In: ANDERSON RC., CHABAUD AG., WILLMOTT S. CIH Keys to the Nematode Parasites of vertebrates, IX. England: Commonwealth Agricultural Bureaux, 1982: 26p.

3 ARAÚJO T., MORO L., LÚCIA M., GOLlOUBEFF B., VASCONCELOS AC. Ocorrência de alguns endo e ectoparasitos no serpentário da Unifenas Universidade de Alfenas - MG. Braz. J. Vet. Res. Anim. Sci., 1999, 36,19-22.

4 ARTIGAS P., ARAUJO P., GRAEIRO A. Redescrição de Acanthorhabdias acanthorhabdias Pereira, 1927. Arq. Inst. Biol., 1973, 40, 33-7.

5 BURKE TJ. Reptile anesthesia. In: FOWLER ME. Eds. Zoo and wild animal medicine. Philadelphia: WB Saunders, 1986, 153-5.

6 FERNANDES MPM., SOUZA SV. Redescrição de Acanthorhabdias acanthorhabdias Pereira, 1927. Mem. Inst. Oswaldo Cruz, 1974, 72, 291-2.

7 KLINGENBERG RJ. Understanding reptile parasites. California: Advanced Vivarium Systems, 1993: 83p.

8 KLOSS GR. Alguns Rhabdias (Nematoda) de Bufo no Brasil. Pap. Avulsos Zool. S. Paulo, 1971, 24, 1-52.

9 MADER DR. Reptile medicine and surgery. Philadelphia: WB Saunders, 1996.

10 PEREIRA C. Fauna helminthologica dos ophideos brasileiros. Bol. Biol. S. Paulo, 1927, 10, 179-85.

11 PEREIRA C. Fauna helminthologica dos ophideos brasileiros. Bol. Biol. S. Paulo, $1928,11,13-22$.

12 REY L. Parasitologia. 3.ed. Rio de Janeiro: Guanabara Koogan, 2001.

13 SILVA RJ., BARRELLA TH., NOGUEIRA MF., O'DWYER LH. Frequency of helmints in Crotalus durissus terrificus (Serpentes, Viperidae) in captivity. Rev. Bras. Parasitol. Vet., 2001, 10, 91-3. 